\title{
Энергоснабжение изолированных территорий
}

\section{в контексте привлечения инвестиций и развития экономики региона}

Анализ электроснабжения изолированных территорий с учетом развития приоритетных направлений экономики региона и оценки чувствительности финансовых параметров потребителей к затратам на электроэнергию определили интерес авторов к данной проблематике и являются целью исследования. В статье представлен синтез проблем энергоснабжения на примере Республики Тыва как одного из регионов с обширными территориями изолированного энергоснабжения и с высокими ценами на энергоресурсы. Даны причины роста стоимости электроэнергии, в том числе и от источников малой генерации, работающих на ископаемых видах топлива. Показано, что ограниченность границ экономически обоснованной передачи электроэнергии при малых нагрузках является основным препятствием для подключения к централизованным системам энергоснабжения на изолированных территориях и ориентирует на преимущественно децентрализованное снабжение. Предложен инструментарий, в соответствии с которым на примере отрасли золотодобычи проводится экономическое обоснование чувствительности финансовых параметров потребителя к стоимости электроэнергии. Авторская гипотеза основана на возможностях технологического развития в области возобновляемых источников энергии, сопровождающегося снижением стоимости строительства объектов их генерации и их эксплуатации. Обосновано, что поскольку экономическая целесообразность использования возобновляемых источников энергии для инвесторов определяется с учетом степени зависимости финансовых параметров потребителей от существующих затрат на генерацию, требуется формирование структуры источников энергии при различных исходных условиях. Для решения этой задачи представлена линейная зависимость рентабельности проектов золотодобычи от стоимости электроэнергии. Предложенные критерии и методы определения пороговых значений экономической эффективности получаемых энергетических услуг от поставщика и электроэнергии, производимой объектами собственной генерации, позволят на стадии дальнейших исследований производить индивидуальный анализ влияния стоимости электроэнергии на финансовые параметры проектов для применения инновационных схем энергоснабжения и на практике выявлять пороги чувствительности рентабельности к снижению затрат на электроэнергию по проектам с различными объемами энергопотребления.

Ключевые слова: инвестиционные проекты, стоимость электроэнергии, источники генерации, плотность энергопотребления, децентрализованное энергоснабжение, возобновляемые источники энергии, финансовые параметры, пороги рентабельности, функции регрессии, аналитическая линейная зависимость

Для цитирования: Асаул А. Н., Асаул М. А., Левин Ю. А., Платонов А. М. Энергоснабжение изолированных территорий в контексте привлечения инвестиций и развития экономики региона // Экономика региона. 2020. Т. 16, вып. 3. С. 884895. https://doi.org/10.17059/ekon.reg.2020-3-16

1 ( ) Асаул А. Н., Асаул М. А., Левин Ю. А., Платонов А. М. Текст. 2020. 
a) Saint Petersburg State University of Architecture and Civil Engineering, Saint Petersburg, Russian Federation

b) Moscow Automobile and Road Construction State Technical University, Moscow, Russian Federation

c) Moscow State Institute of International Relations, Moscow, Russian Federation

d) Ural Federal University, Ekaterinburg, Russian Federation

a) http://orcid.org/0000-0002-7415-4737

b) http://orcid.org/0000-0003-3040-5765

c) http://orcid.org/0000-0002-9568-7866

d) http://orcid.org/0000-0002-1199-0578, e-mail: a.m.platonov@urfu.ru

\section{Energy Supply to Isolated Areas: Attracting Investment and Developing Regional Economy}

The study analyses energy supply to isolated areas considering the development of priority areas of the regional economy and assessing the dependence between consumer finances and electricity costs. We examined energy supply problems in the example of the Tuva Republic, the Russian region with vast isolated areas and high prices for energy. We explained the reasons for the increase in electricity costs, including small-scale generation sources based on fossil fuels. The limitations of economically substantiated energy transmission at light loads prevent the connection to a centralised energy supply systems in isolated territories, leading to a decentralised energy supply. Thus, we proposed a methodological toolkit for solving the problem of economic substantiation of the dependence between consumer finances and electricity costs, testing it on the example of the gold mining industry. Our hypothesis relies on technological development opportunities in the field of renewable energy sources to reduce the construction and operation costs of generation facilities. Since the economic feasibility of using renewable energy sources for investors is determined by the dependence of consumer finances on energy generation costs, it is necessary to create energy resource structures depending on different basic conditions. For that purpose, we showed the linear dependence of the profitability of gold mining investment projects on electricity costs. The proposed criteria and methods allow determining the threshold values of the economic efficiency of energy services provided by suppliers and energy produced by self-generating facilities. Based on these results, further research can focus on analysing the impact of electricity costs on the financial parameters of projects to apply innovative energy supply schemes and identifying thresholds of the response of profitability to energy costs reduction for different energy consumption projects.

Keywords: investment projects, electricity costs, generation sources, energy density, decentralised energy supply, renewable energy sources, financial parameters, profitability thresholds, regression functions, analytical linear dependence

For citation: Asaul, A. N., Asaul, M. A., Levin, Yu. A. \& Platonov, A. M. (2020). Energy Supply to Isolated Areas in the Context of Attracting Investment and Developing Regional Economy. Ekonomika regiona [Economy of region], 16(3), 884-895, https:// doi.org/10.17059/ekon.reg.2020-3-16

\section{Введение}

Территории России, имеющие автономное энергоснабжение, составляют около 65 \% от общей площади страны На них проживает примерно 20 млн чел. [1]. Республика Тыва в составе Российской Федерации относится к данному виду территорий. В республике централизованным электроснабжением охвачено 68 \% территории. Из 17 муниципальных районов республики 11 имеют централизованное энергоснабжение, 3 - децентрализованное и 3 - смешанное энергоснабжение [2, с. 21].

Тува - единственный в Сибири регион, где максимальная электрическая нагрузка ограничена явно недостаточными для региона суммарными возможностями подачи электроэнергии. Энергетическая система Республики Тыва является дефицитной. Собственная выработка не позволяет покрыть существующие потребности. Собственными электрогенерирующими источниками может быть по- крыто только 11,2 \% максимальной электрической нагрузки. Значительная часть республики - изолированные территории с децентрализованным электроснабжением, составляющие 32 \% площади региона [3].

Все это делает актуальным для региона анализ экономической целесообразности новых вариантов электроснабжения изолированных территорий с учетом оценки чувствительности финансовых параметров наиболее характерных потребителей к затратам на электроэнергию. В этом заключается цель данной работы, ставящей задачи определения степени зависимости финансовых параметров инвестиционных проектов от стоимости электроэнергии на изолированных территориях и поиск на основе предложенных подходов пороговых значений стоимости электроэнергии, получаемой от поставщика или производимой ее объектами собственной генерации, при различных уровнях рентабельности предприятия. 
Хотя Республика Тыва законодательно отнесена к регионам, имеющим большое число изолированных систем энергоснабжения с высокими затратами на энергию ${ }^{1}$, имеет место, по мнению авторов, невысокая наглядность проблемы влияния стоимости электроэнергии на перспективы реализации инвестиционных проектов, что обусловлено относительно малыми размерами электроснабжения Тувы. Поэтому проблематику перспективных масштабов инвестиций Тувы необходимо раскрыть в контексте решения задач, связанных с использованием новых систем децентрализованного энергоснабжения в условиях, когда удельная установленная мощность на душу населения в отдельных населенных пунктах Республики Тыва не соответствует нормативам и значительно колеблется - от 0,11 вт/чел. до 4 вт/чел., примерно 82 \% территории республики занимают горы с чередованием высоких хребтов и глубоких котловин, а 2,1\% - сельскохозяйственные угодья [2, с. 22].

Социально-экономические особенности существования децентрализованной энергетики заключаются в резко континентальном климате, удаленности и труднодоступности потребителей, в низкой плотности населения и небольших мощностях энергогенерирующих установок, отсутствии крупных промышленных потребителей; аграрной специализации районов [2, с. 23]. При этом к сильным сторонам территории Тывы можно отнести весьма существенные балансовые запасы каменного угля, оцениваемые в 11 млрд т, а также соответствующие климатические условия для развития солнечной энергетики как при строительстве электростанций от 5 МВт и более, так и для автономного энергоснабжения [2, с. 25]. Для коренного улучшения сложившейся ситуации в сфере энергетики Республики Тыва разработаны и утверждены государственная программа «Энергоэффективность и развитие энергетики на 2014-2020 годы (с изменениями на 21 февраля 2019 года)» и Стратегия развития топливно-энергетического комплекса Республики Тыва на период до 2030 года.

Республики Тыва и Хакасия, Красноярский край и Иркутская область взаимосвязаны в едином экономико-географическом пространстве, образующем Ангаро-Енисейский макрорегион. Экономический потенциал и масштаб

\footnotetext{
${ }^{1}$ О внесении изменений в перечень районов Крайнего Севера и приравненных к ним местностей с ограниченными сроками завоза грузов (продукции). Постановление правительства РФ от 6 декабря 2016 г. № 1305.
}

реализуемых в Ангаро-Енисейском макрорегионе инвестиционных проектов обусловлены его геополитическим значением и ресурсной базой, существующими межправительственными соглашениями и контрактами по экспорту, а также емкостями рынков граничащих с ним стран Азиатско-Тихоокеанского региона и Северо-Восточной Азии [4, с. 286].

На территории Тувы реализуются стратегические цели государства, среди которых контроль над важнейшими запасами сырьевых ресурсов и эффективностью их эксплуатации, расширение торгово-транспортного пространства России на Восток. Стратегия пространственного развития Российской Федерации до 2025 года предусматривает в Тыве как наращивание промышленного потенциала, так и развитие ее инфраструктурного пространства.

Согласно стратегии социально-экономического развития Ангаро-Енисейского макрорегиона, стабильное развитие промышленности и инфраструктурного пространства является основным драйвером экономики, требующим масштабных инвестиций, а значит - нового уровня рентабельности, благодаря которому экономическая деятельность в макрорегионе будет привлекательной для инвесторов. Рост экономики основан на увеличении добычи серебра и золота, меди и никеля, угля и других полезных ископаемых, на переработке продукции в минерально-сырьевой и лесной промышленности. Основной задачей на среднесрочную и долгосрочную перспективы развития для Ангаро-Енисейского макрорегиона является увеличение доли обрабатывающего сектора с высокой долей добавленной стоимости и формирование современной транспортно-логистической инфраструктуры [4, с. 287].

На территории Тывы преградой на пути реализации этих проектов является неразвитость ее энергетической инфраструктуры, приводящая к ее дороговизне по совокупности затрат, что создает проблемы с реализацией проектов, требующих опережающего развития. Решение этого вопроса невозможно без мер государственной поддержки по привлечению необходимых объемов инвестиционных средств для реализации крупных проектов. Развитие инфраструктуры и освоение ресурсной базы Ангаро-Енисейского экономического района предусмотрено комплексным инвестиционным проектом (КИП) «Енисейская Сибирь», направленным на развитие трех регионов: Красноярского края, Республики Тыва и Хакасии. Он получил статус приоритетного 
проекта и включен в Стратегию пространственного развития РФ [4, с. 288].

\section{Теоретическая основа исследования}

Теоретическую основу исследования заложили труды современных российских и зарубежных ученых, изучавших проблемы экономического развития регионов и формирование их конкурентных преимуществ (Н.Л. Зубаревич， Г.Ф. Балакина， А.Н. Швецов, Д. Фридманн и др.) [5-10]. Различия в степени регионального эффекта в связи с различной структурой приведенных затрат энергоемких и неэнергоемких технологий, учитываемые при разработке стратегий развития электрификации страны, выявлялись ранее в СССР еще в 60-70-гг. XX в.; изучались перспективы альтернативной энергетики, хотя в промышленных аспектах основной акцент делался на атомные станции. Тогда же начали проводиться исследования, посвященные экономике освоения альтернативных источников энергии в СССР, в контексте которых давалась оценка эффективности применения электростанций малой мощности: гидроэлектростанций 1501000 кВт, солнечных и ветряных электростанций 50-150 кВт с учетом действия региональных факторов (природных, экономических, технических), находящих количественное отражение в величине и структуре приведенных затрат; рассчитывались удельные приведенные затраты (на производство единицы продукции) по традиционной и альтернативной схемам электроснабжения в зависимости от территориального размещения производств различных отраслей промышленности в укрупненных регионах страны [11]. Однако достаточно широкого практического внедрения эти теоретические исследования в тот период не получили.

Результаты изучения современного состояния, тенденций и движущих сил развития альтернативной энергетики, отраженные в трудах как отечественных ученых (П.П. Безруких, В.П. Шуйский и др.) [12-15], так и зарубежных (Б. Соренсен, Д. Твайдел, А. Уэйр и др.) [1622], ориентируют на проведение исследований по оценке возможностей динамично развивающегося направления энергетики, основанного на использовании возобновляемых источников, в т. ч. в технологически изолированных территориальных системах. В трудах О.А. Суржиковой [23] сделаны выводы о приоритетности использования возобновляемых источников энергии в условиях российской экономики для удаленных и малонаселенных районов. Однако работ по экономическому анализу энергоснабжения изолированных территорий с изложением критических стоимостных оценок энергозатрат и с учетом развития приоритетных направлений экономики региона крайне мало.

Незавершенность, по мнению авторов, существующих разработок, представляющих множество разрозненных исследований, затрудняет решение задач, направленных на реализацию новых проектов хозяйственного освоения территорий изолированного энергоснабжения с присущими им проблемами, в том числе вызванными крайне ограниченным применением традиционных схем поставок электроэнергии от крупных электростанций; дефицитом энергии и ее дороговизной из-за многозвенных транспортных схем доставки топлива. Все вместе негативно отражается на развитии экономики региона.

Остаются также недостаточно изученными экономические вопросы использования систем децентрализованного энергоснабжения в контексте реализации промышленного потенциала региона с учетом особенностей его территории и долговременных национальных интересов. Обобщение результатов собственных многолетних научных трудов авторов данного исследования в области региональной экономики, привлечение обширных фактических материалов определяет необходимость изучения ряда указанных вопросов применительно к современным условиям с учетом существенной специфики объекта исследования - Республики Тыва.

\section{Методы и приемы исследования}

В статье использовались следующие методы и приемы научного исследования: системный подход; сравнительный многофакторный анализ для выявления проблем региональных энергопотребителей; финансово-экономические расчеты при оценке зависимости рентабельности инвестиционного проекта по освоению золоторудного месторождения от затрат на электроэнергию; регрессионный анализ, используемый в отечественной и зарубежной практике.

\section{Исследование}

Планы реализации ряда новых проектов на территории Тувы сдерживаются в определенной мере двойственностью и противоречивостью ее инфраструктуры, усугубляющей трудности с привлечением инвесторов. С одной стороны, мощные природно-ресурс- 
ные и географически-территориальные потенциалы республики являются резервами ее устойчивого социально-экономического развития. Но с другой - дефицит генерирующих мощностей и ограниченная пропускная способность межсистемных линий электропередач, тупиковая система электроснабжения и отсутствие крупных потребителей означают слабую насыщенность территории Тувы факторами производства и существенные инфраструктурные ограничения из-за низкого уровня развития энергетической инфраструктуры, значительного количества изолированных систем энергоснабжения с высокими затратами на энергию и невозможности формирования централизованной энергосистемы по всей территории.

Установление отпускной цены на электроэнергию, основанное на принципе «затраты плюс», является неэффективным как для местных энергетиков, так и для ее потребителей. Сейчас в Туве она выше среднероссийской, хотя цены и выручка энергокомпаний Республики Тыва растут значительно медленнее, чем их затраты [24]. Энергоснабжение Тувы субсидируется из бюджета региона на компенсацию выпадающих доходов организаций. При этом стоимость услуг по межрегиональному перетоку электроэнергии в Туву по федеральным электрическим сетям возрастает ежегодно, что снижает рентабельность хозяйствующих субъектов и сдерживает реализацию многих долгосрочных программ инвестирования в экономику Тувы в формате мегапроекта «Енисейская Сибирь». Это особенно касается энергоемких производств из числа не имеющих собственных источников генерации, и в первую очередь - базовых организаций по видам экономической деятельности «добыча полезных ископаемых» и «обрабатывающие производства», в которых из-за высоких тарифов на электроэнергию многие крупные по масштабам энергопотребления инвестиционные проекты находятся на грани рентабельности.

Нерегулируемая цена на электроэнергию, которая приобретается для Республики Тыва на оптовом рынке, возрастала более чем на $10 \%$ ежегодно [2, с. 22]. Основной фактор - малый объем электропотребления в Туве по сравнению с другими энергетическими компаниями Ангаро-Енисейского макрорегиона невзирая на то, что среднегодовой темп прироста потребления электроэнергии в Туве за последние 10 лет составляет около 4 \%. В соседних регионах со значительно большими объемами электропотребления (например, в Хакасии осущест-

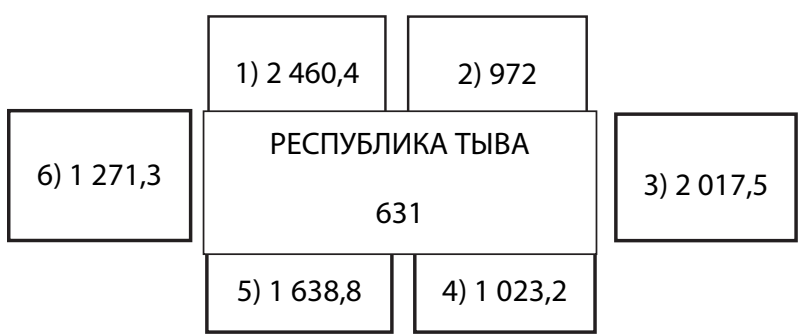

Рис. 1. Энергетическое окружение Республики Тыва, в KBm.час/душу населения в среднем (1 - Иркутская область;2 - Республика Бурятия; 3 - Монголия; 4 - Республика Алтай; 5 - Республика Хакасия; 6 Красноярский край)

Figure 1. Energy environment of the Tuva Republic in kW. hour / capita on average (1 - Irkutsk region; 2 - Republic of Buryatia; 3 - Mongolia; 4 - The Altai Republic; 5 - Republic of Khakassia; 6 - Krasnoyarsk region)

вляется передача электроэнергии по своим электрическим сетям - в объеме в 20 с лишним раз больше, чем в Туве, а в Иркутской области - примерно в 100 раз больше, чем в Туве), цена на 15-20 \% ниже ${ }^{1}$.

Энергетическое окружение Республики Тыва является довольно благоприятным (рис. 1), особенно со стороны Иркутской области, Монголии и Красноярского края. Однако действие двух таких факторов, как экономический, проявляющийся в виде отсутствия в регионе крупных промышленных потребителей, и природно-географический фактор, заключающийся в горном рельефе Тувы и ряда ее соседей по макрорегиону, препятствуют формированию регулярных, достаточных по объему и доступных по стоимости перетоков электроэнергии. Поэтому в ближайшем будущем проблема обеспечения республики энергоресурсами остается в парадигме изолированного энергоснабжения.

Сложившаяся ситуация в энергоснабжении Тувы затрагивает общие интересы экономики Ангаро-Енисейского макрорегиона и требует экономического обоснования энергетических тарифов в первую очередь для производственных потребителей с точки зрения сравнительной рентабельности с другими регионами. Более 90 \% электроэнергии Тува получает из Хакасии. Поскольку многие районы из-за труднодоступности не подключены к региональной электросети, то для территории Тувы характерно большое число изолированных сетей, обслуживаемых источниками малой генерации (дизельными электро-

\footnotetext{
${ }^{1}$ Объем потребления электроэнергии на душу населения // Ассоциация «НП Совет рынка». URL: https://www.np-sr. $\mathrm{ru} / \mathrm{ru} / \mathrm{SR} \_16911$.
} 
станциями). Преимущественно изолированное энергообеспечение труднодоступных районов Тувы осуществляется отдельно в каждом поселении при помощи дизельных электростанций (ДЭС), топливо для которых доставляют один раз в год в рамках так называемого северного завоза. Срок завоза в эти районы ограничен, так как до них можно добраться только по воде и через переправы, действующие в летний период.

Стоимость дизельного топлива, поставляемого в Туву с нефтеперегонных заводов Сибири, возрастает почти ежегодно. В итоге для Тувы стоимость завоза топлива в труднодоступные районы многозвенными транспортными схемами доставки примерно в полтора раза превышает стоимость дизельного топлива для центральных регионов России. При этом проблема высокой себестоимости производства электроэнергии на ДЭС, характеризующихся преимущественно низким КПД и ростом удельного расхода топлива на выработку электроэнергии остается не разрешимой.

Можно выделить два фактора удорожания электроэнергии от традиционных источников малой генерации. Первый фактор является непосредственным следствием постоянного удорожания дизельного топлива и роста стоимости его транспортировки. Второй фактор связан с падением объемов полезного отпуска электроэнергии из-за снижения потребности в слаборазвитом регионе (сокращается численность населения, уменьшается объем производимой продукции и др.) при сравнительно устойчивом значении условно-постоянных расходов на генерацию электроэнергии дизельных электроустановок. Таким образом в республике происходит практически постоянный рост экономически обоснованных затрат на электроэнергию.

Подобная ситуация с высокими затратами на электроэнергию не только отражается на условиях жизнедеятельности населения, но и затрудняет развитие реального сектора экономики республики, препятствуя реализации таких конкурентных преимуществ, как выгодное географическое и приграничное положение, наличие запасов лесосечного фонда, минерально-сырьевое богатство и разведанные запасы полиметаллических руд.

Республика Тыва без запуска со стороны федеральной власти соответствующих механизмов стимулирования потребителей при переходе на новые источники энергоснабжения малой генерации не может стать конкурентоспособной среди других территорий Ангаро-
Енисейского макрорегиона и, в первую очередь, экономически развитой южной части Красноярского края, которая, в отличие от территории Тувы, характеризуется выраженной специализацией, значительно более высоким уровнем развития перерабатывающей промышленности и ресурсных отраслей, сравнительно высоким уровнем развития инфраструктуры и человеческого капитала $[24,25]$.

Конечно, экономически доступная электроэнергия - не единственный фактор оценки конкурентных преимуществ территории. На инвестиционную привлекательность влияют также многие другие факторы, среди которых транспортная доступность, логистика и др. Однако приток инвестиций, необходимый для развития региона, в значительной мере зависит от уровня затрат на электроэнергию. Решению этой задачи могут способствовать программы применения типовых решений по использованию возобновляемых источников энергии (ВИЭ) для изолированных территорий при условии реализации возможности снижения операционных издержек и одновременного обеспечения надежных энергетических услуг [26, 27].

Успешный мировой и российский опыт повышения энергоэффективности и развития ВИЭ подтверждает возможность перспективного решения весьма острой в социальном и техническом аспектах стратегической задачи надежного и качественного электроснабжения населения и промышленных потребителей, рассредоточенных по территории региона ${ }^{1}$.

В мире в нынешнем десятилетии использование ВИЭ возросло в 4 раза (без учета гидроэнергетики), но при этом доля ВИЭ в общем мировом потреблении энергоресурсов не превышает $2 \%^{2}$. «Хотя в целом энергия ВИЭ остается пока дороже традиционной, на отдельных участках эти источники уже сейчас оказываются конкурентоспособными, сокращая, по сравнению с традиционными, если не удельное потребление энергии, то ее стоимость» [28]. В нашей стране затраты по производству электроэнергии на основе ВИЭ, финансируемой исключительно за счет рынка, по-прежнему выше, чем в централизованной энергетике. Снижение ее концептуально возможно либо за счет усиления мер государственной поддержки, либо за счет технологического развития в области возобновляемых

\footnotetext{
${ }^{1}$ Энергоснабжение изолированных территорий в России и мире // Энергетический Бюллетень. № 51. 2017. С. 14-18. ${ }^{2}$ BP Statistical Review of World Energy, June 2019.
} 
источников энергии, сопровождающегося снижением как стоимости строительства объектов их генерации, так и стоимости их эксплуатации. Авторы в настоящем исследовании гипотетически допускают формирование второй концепции.

Вместе с тем следует признать, что наряду с достаточно многочисленными исследованиями, посвященным преимущественно техническим характеристикам источников ВИЭ, имеется крайне мало работ, которые бы анализировали эти источники в контексте экономической целесообразности их освоения. Достаточно много популистских публикаций в сфере применения ВИЭ. Следует также отметить, что возможности применения ВИЭ сама альтернативная энергетика рассматриваются чаще всего обособленно, вне взаимосвязи с финансовыми параметрами проектов применения.

За последние два десятилетия концептуальные и стратегические основы энергетической политики в стране претерпели ряд изменений ${ }^{1}$, однако приоритеты в этой сфере остаются неизменным, в том числе и в части решения задачи применения ВИЭ по приемлемым ценам для изолированных систем энергоснабжения с высокими затратами на энергию2.

Согласно Энергетической стратегии России на период до 2030 года, производство ВИЭ в стране должно возрасти более чем в 9 раз, мощность - в 11 раз, а общая доля ВИЭ в балансе страны составит $4,5 \%^{3}$, что примерно в 3 раза превышает нынешний показатель, но вместе с тем значительно отстает от мировых долгосрочных ориентиров в 40 \% [29] и будучи столь далекой от современных и перспективных показателей мировых держав-лидеров не может устраивать Россию. Однако остается открытым вопрос о приемлемых для потребителя с точки зрения ожидаемой рентабельности его проектов затратах на собственную генерацию на основе ВИЭ или на покупку электроэнергии у гаранти-

\footnotetext{
Основные направления государственной политики в сфере повышения энергетической эффективности электроэнергетики на основе использования возобновляемых источников энергии на период до 2020 года. Распоряжение Правительства Российской Федерации от 8 янв. 2009 г. № 1-р // Собрание законодательства Российской Федерации. 2009. № 4. Ст. 515.

2 О6 электроэнергетике. Федеральный Закон №35-Ф3. С изм., вступившими в силу с 01.01.2019 г.

3 Энергетическая стратегия России на период до 2030 года. Утв. распоряжением Правительства РФ от 13 ноября 2009 г., № 1715-p.
}

рующего поставщика по розничным ценам. В приводимых далее результатах авторских исследований предлагаются методические подходы для анализа зависимости финансовых параметров инвестиционного проекта от стоимости электроэнергии.

\section{Результаты исследования}

Для анализа сравнительных издержек и оценки чувствительности финансовых параметров проекта к стоимости электроэнергии выбраны в качестве примера золотодобывающие производства не только потому, что источники золотодобычи чаще всего изолированы от централизованного энергоснабжения. Энергосырьевой сценарий развития России дает мощный импульс развитию Тувы в виде масштабного освоения ее наиболее ценного природных богатства - золотодобычи.

Золотодобыча в Туве имеет огромное значение в ее социально-экономической жизни и в создании валового регионального продукта. Она является одним из приоритетных направлений экономики региона и макрорегиона (в 2018 г. в Туве добыто 1,45 т золота), формирует налогооблагаемую базу и обеспечивает занятость населения, в первую очередь, муниципальных образований, на территории которых ведется золотодобыча. Развитие золотодобычи - это существенный источник пополнения бюджетов всех уровней, рабочие места, зарплата и поддержка социальных проектов Тувы ${ }^{4}$. К этому следует добавить, что в СутХельском районе республики открыто три перспективных участка с содержанием золота от 0,7 ч/м до 5,8 ч/м мощностью от 1 м до 3 м.

Месторождения золота, представляющие потенциальный интерес для инвесторов, чаще всего залегают на изолированных территориях, вне населенных пунктов. Поскольку централизованное энергоснабжение экономически нецелесообразно для золотодобычи из-за малых нагрузок и низкой плотности энергопотребления, инвесторам приходится обеспечивать собственную генерацию как альтернативу подключения к единой энергосистеме. Оба варианта электроснабжения предполагают необходимость предварительного выполнения соответствующих расчетов, чтобы выяснить, готов ли инвестор нести такие затраты. От выбора рационального решения по применению электроэнергии в производстве золотодобычи

\footnotetext{
Стратегия социально-экономического развития Республика Тыва до 2030 года // Министерство экономического развития РФ. URL: economy.gov.ru.
} 
Таблица Анализ зависимости финансовых параметров инвестиционного проекта по освоению золоторудного месторождения от стоимости электроэнергии [30, с. 32]

Table

Analysis of the dependence of financial parameters of an investment project for the development of a gold ore mine on electricity costs [30, p. 32]

\begin{tabular}{|c|c|c|}
\hline \multicolumn{3}{|c|}{ Значения показателей проекта } \\
\hline $\begin{array}{c}\text { Стоимость электроэнергии, } \\
\text { руб. / кВт.ч }\end{array}$ & $\begin{array}{l}N P V, \\
\text { млн долл. }\end{array}$ & $I R R, \%$ \\
\hline 2,253 & 53,6 & 13,9 \\
\hline 2,503 & 42,0 & 13,6 \\
\hline 2,753 & 30,3 & 13,3 \\
\hline 3,003 & 19,0 & 13,0 \\
\hline 3,253 & 7,7 & 12,7 \\
\hline 5,753 & 107,0 & 9,9 \\
\hline 6,003 & 118,7 & 9,6 \\
\hline 6,253 & 130,5 & 9,3 \\
\hline 6,503 & 142,2 & 9,1 \\
\hline 6,753 & 153,9 & 8,8 \\
\hline 7,003 & 165,7 & 8,6 \\
\hline 7,253 & 177,4 & 8,3 \\
\hline 7,503 & 189,2 & 8,0 \\
\hline 7,753 & 201,0 & 7,8 \\
\hline 8,003 & 212,9 & 7,5 \\
\hline 8,253 & 224,7 & 7,3 \\
\hline
\end{tabular}

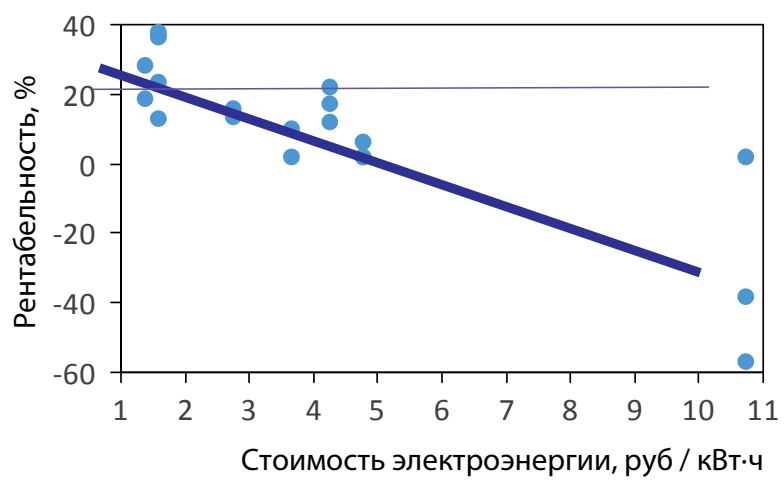

Рис. 2. Определение зависимости рентабельности золотодобывающих производств от стоимости электроэнергии

Figure 2. Dependence of the profitability of gold mining on electricity costs

при экономически эффективной для инвестора стоимости электроэнергии в значительной степени зависит рентабельность инвестиционного проекта.

Для экономического обоснования затрат на электроэнергию при реализации различных схем энергоснабжения промышленных потребителей региона используется «предпроектная проработка параметров инвестиционного проекта по развитию золоторудного месторождения, которая позволила оценить чувствительность финансовых параметров инвестицион- ного проекта к стоимости (тарифам) электроэнергии [30, с. 32]» (табл.).

В качестве критерия принимается чувствительность финансовых параметров золотодобычи к стоимости (тарифам) электроэнергии для потребителей на изолированных территориях. Гипотезой для формирования сценарных условий является реализация комплекса технологических возможностей снижения стоимости строительства и операционных издержек в системах энергоснабжения на основе ВИЭ. «Ограничивающими условиями являются значения чистого дисконтированного дохода (положительное значение Net Present Value $N P V)$ и величина внутренней нормы доходности - (Internal Rate of Return - IRR)» [30, с. 33]. Проведенные расчеты позволили определить зависимость порогов рентабельности золотодобывающих производств от стоимости электроэнергии (рис. 2).

«На основании проведенных расчетов получен набор точек, показанный на рисунке 2, позволивший построить наклонную линию как результат приближения (регрессия)» [30, c. 34]. Таким образом получена приближенная аналитическая линейная зависимость:

$$
y=-0,0628 x+0,3605,
$$

или при умножении рентабельности на $100 \%$ :

$$
y=-6,28 x+36,05 \text {. }
$$

Это означает, что при «бесплатной» условно электроэнергии рентабельность будет 36,05 \% и далее при увеличении стоимости на каждый 1 руб/(кВт·ч) рентабельность будет уменьшаться на 6,28 \%.

\section{Заключение}

Сформулированные условия перспективного внедрения современных вариантов автономного электроснабжения и предлагаемые подходы к экономическому обоснованию энергозатрат для промышленных потребителей на предпроектной стадии основаны на поиске тех пороговых значений стоимости электроэнергии, при которых получение энергетических услуг от поставщика или производство ее объектами собственной генерации соответствует определенному уровню рентабельности проекта и позволяют учесть изменения экономических показателей электроснабжения за счет снижения операционных издержек в энергосистемах на основе ВИЭ.

Решение задачи, ориентированной на выявление предельных значений, дает возможность инвестору на стадии бизнес-проекта 
провести анализ сравнительных издержек промышленных потребителей при различных затратах. Индивидуальный анализ влияния стоимости электроэнергии на финансовые параметры проектов при применении инновационных схем энергоснабжения выявляет пороги чувствительности рентабельности к снижению затрат на электроэнергию по перспективным проектам с различающимися по масштабам объемам энергопотребления.

К инвестиционным проектам в горно-таежной местности на территории Тувы, помимо развития месторождений золотодобычи, можно отнести разработку медно-порфирового месторождения, угледобычу и углеобогащение, строительство горно-обогатительных комплексов, заводов глубокой переработки древесины и ряд других проектов [31, 32]. Часть рассмотренных проектов уже реализована в 2015-2018 гг., что не снижает актуальности вопросов электроснабжения, а часть в стадии реализации. Вместе с тем, реализация некоторых проектов на изолированных тер- риториях может быть отложена, если они окажутся нерентабельными или будут находиться на грани рентабельности. В эту категорию попадают не только энергоемкие проекты строительства промышленных предприятий, не имеющих возможности развивать собственную генерацию, работающую на побочных и вторичных ресурсах, нуждающиеся в мерах бюджетной поддержки по финансированию дорогостоящего строительства линий электропередач для подключения к единой энергосистеме, но и различные проекты малой энергоемкости, от которых также зависит весомая часть экономики региона.

Разработка программ применения собственной генерации с использованием ВИЭ по экономически приемлемым ценам и внедрением механизмов стимулирования потребителя способна решить сложный вопрос распределенной институциональной и экономической ответственности за надежное и экономичное энергоснабжение реализуемых инвестиционных проектов на изолированных территориях.

\section{Список источников}

1. Елистратов В.В. Возобновляемая энергетика. СПб. : Санкт-Петербургский политехнический университет Петра Великого, 2016. 424 с.

2. Кенден К.В. Анализ состояния энергоснабжения населенных пунктов Республики Тыва и перспективы его совершенствования // Вестник тувинского государственного университета. Технические и физико-математические науки. 2017. № 3. С. 20-33.

3. Балакина Г. Ф., Куликова М. П. Исследование энергетической безопасности Республики Тыва // Региональная экономика: теория и практика. 2012. № 37. С. 36-41.

4. Levin Y.A., Asaul A.N. Tools of the territory competitive advantages realization in the depressed region // The European Proceedings of Social \& Behavioural Sciences EpSBS. Vol. LXXVII- MTSDT. 2019. P. 285-291.

5. Зубаревич Н. В. Стратегия пространственного развития: приоритеты и инструменты // Вопросы экономики. 2019. № 1. C. 135-145. DOI: 10.32609/0042-8736-2019-1-135-145.

6. Balakina G. F. Specifics of forming a regional socioeconomic development strategy in the context of modernization // Regional Research of Russia. 2015. T. 5. № 3. P. 270-275.

7. Inclusive growth: a dataset on key and institutional foundations for inclusive growth / R. I Sharafutdinov, E. M. Akhmetshin, A. G. Polyakova, et all // Data in Brief. 2019. T. 23. P. 103864. DOI: 10.1016/j.dib.2019.103864.

8. Shvetsov A. N. Growth points or black holes: how efficient are state stimulation tools for territorial development? // Regional Research of Russia. 2017. T. 7, № 2. P. 108-119. DOI: 10.1134/S2079970517020071.

9. Friedmann J., Weaver C. Territory and Function: The Evolution of Regional Planning. Berkeley, CA : University of California Press, 1979. 240 p.

10. Friedmann J. Regional Development Policy. Boston, Mass. : Inst. Techn., 1966. 317 p.

11. Современные проблемы электрификации и электроэнергетики. Сб. науч. тр. М. : ЭНИН им. Г. М. Кржижановского, 1983. 257 с.

12. Bezrukikh P.P., Strebkov D.S. Reneweable Energy in the Third Millennium: Outlook From Russia. // Materials of Business and Technical Seminar for Power Engineering (Oct., 16-17, 2002). Capetown, 2002. 115 p. P. 5-9.

13. Шуйский В.П., Алабян С.С., Морозенкова О.В. Возобновляемые источники энергии в первой половине XXI в. // Россия и современный мир. 2012. № 1. С. 118-132.

14. Ermolenko G. V., Proskuryakova L.I., Ermolenko B. V. Switching to renewables: what will Russia gain? // Foresight. 2017. T. 19, № 5. P. 528-540.

15. Чапльгина М.А., Белоусов Р.С. Мировой опыт автономного энергоснабжения для российской глубинки // Аллея науки. 2017. Т. 2, № 16. С. 464-474.

16. Elliott D. Renewables: A Review of Sustainable Energy Supply Options. New York : IOP Publishing Ltd, $158,2013$. $158 \mathrm{p}$.

17. Shere J. Renewable: The World-Changing Power of Alternative Energy//. New York : St Martin's Press, 2013.304 p. 
18. Sorensen B. Renewable Energy, Fourth Edition: Physics, Engineering, Environmental Impacts, Economics \& Planning. New York : Academic Press, 2017. 1056 p.

19. Rehfeldt K. Windenergie nutzung in der Bundesrepublin Deutchland // DEWI Magazin. 1996. № 9. P. 15-27.

20. Twidell J. W., Weir A. D. Renewable Energy resources. London : F. N. Spon, 1986. 391 p.

21. Cirelli J. F., Sire D. Lénergie est un secteur où il faut être grand // Nouvelles Fondations. 2007. № 2. P. 75-78.

22. Burrows M., Treverton G. Strategic View of the Energy Future. Washington : GPO, 2008. 142 p.

23. Суржикова О.А. Обеспечение электроэнергией труднодоступных, малонаселенных и удаленных регионов // Региональная экономика. Теория и практика. 2010. № 11. С. 67-72.

24. Кужугет С.А., Кенден К.В. Перспективы развития децентрализованной энергетики в Республике Тыва // Актуальные вопросы энергетики. Мат-лы всерос. науч.-практ. конф. с междунар. участием. Омск, 17 мая 2018. Омск : Издательство ОмГТУ, 2018. С. 185-187.

25. Sustainable development of territories based on the integrated use of industry, resource and environmental potential / O. Yu. Voronkova, L. A. Yakimova, I. I. Frolova, et. all // International Journal of Economics and Business Administration. 2019. T. 7, № 2. Р. 151-163.

26. Велькин В.И. Методология расчета комплексных систем ВИЭ для использования на автономных объектах. Екатеринбург : УрФУ, 2015. 225 с.

27. Низкоуглеродные решения против «экономики сжатия» / Башмаков И. А., Борисов К. Б., Дзедзичек М. Г., Лебедев О. В., Лунин А. А. // Экологический вестник России. 2017. № 11. С. 14-20.

28. Каныгин П. С. Альтернативная энергетика в ЕС. Ее возможности и пределы // Экономист. 2010. № 1. С. 57.

29. Дакалов М. В. Экономические аспекты развития возобновляемых источников энергии в странах ЕС : дисс. канд. экон. наук. М., 2015.

30. Левин Ю.А., Павлов А. О. Дальневосточные инвестиционные проекты. Влияние стоимости электроэнергии на финансовые показатели // Финансовый бизнес. 2017. № 1 (186). С. 31-34.

31. Асаул А.Н., Сагаан-Оол К.Б., Севек В.К. Формирование и реализация промышленной политики региона. Кызыл: РИО ТувГУ, 2014. 167 с.

32. Донгак Б.А. Организация предпринимательской деятельности посредством создания этнокластеров в Республике Тыва : дисс. канд. экон. наук. СПб., 2015. 159 с.

\section{References}

1. Elistratov, V. V. (2016). Vozobnovlyaemaya energetika [Renewable energy]. Saint Petersburg: Saint Petersburg Polytechnic University n.a. Peter the Great, 424. (In Russ.)

2. Kenden, K. V. (2017). Analysis of the state of power supply of settlements of Tuva Republic and prospects of its improvement. Vestnik Tuvinskogo gosudarstvennogo universiteta. № 3. Tekhnicheskie i fiziko-matematicheskie nauki [Vestnik of Tuvan State University. Issue 3. Technical sciences, physical and mathematical Sciences], 3, 20-33. (In Russ.)

3. Balakina, G. F. \& Kulikova, M. P. (2012). Research of power safety of the Tuva Republic. Regionalnaya ekonomika: teoriya i praktika [Regional economics: theory and practice], 37, 36-41. (In Russ.)

4. Levin, Yu. A. \& Asaul, A. N. (2019). Tools of the territory competitive advantages realization in the depressed region. The European Proceedings of Social \& Behavioural Sciences, LXXVII-MTSDT, 285-291.

5. Zubarevich, N. V. (2019). Spatial development strategy: priorities and instruments. Voprosy ekonomiki, 1, $135-145$. (In Russ.)

6. Balakina, G. F. (2015). Specifics of forming a regional socioeconomic development strategy in the context of modernization. Regional Research of Russia, 5(3), 270-275.

7. Sharafutdinov, R. I., Akhmetshin, E. M., Polyakova, A. G., Gerasimov, V. O., Shpakova, R. N. \& Mikhailova, M. V. (2019). Inclusive growth: a dataset on key and institutional foundations for inclusive growth. Data in Brief, 23, 103864.

8. Shvetsov, A. N. (2017). Growth points or black holes: how efficient are state stimulation tools for territorial development? Regional Research of Russia, 7(2), 108-119.

9. Friedmann, J. \& Weaver, C. (1979). Territory and Function: The Evolution of Regional Planning. Berkeley, CA: University of California Press, 240.

10. Friedmann, J. (1966). Regional Development Policy. Boston: MIT, 317

11. Sovremennye problemy elektrifikatsii i elektroenergetiki. Sb. nauch. tr. [Modern problems of electrification and electric power industry: Collection of scientific papers]. (1983). Moscow: ENIN n.a. G. M. Krzhizhanovskiy, 257. (In Russ.)

12. Bezrukikh, P. P.\& Strebkov, D. S. (2002). Reneweable Energy in the Third Millennium: Outlook From Russia. In: Materials of Business and Technical Seminar for Power Engineering (October, 16-17, 2002) (pp. 5-9). Capetown.

13. Shuysky, V. P., Alabyan, S. S. \& Morozenkova, O. V. (2012). Renewable energy sources in the first half of the 21 st century. Rossiya i sovremennyy mir [Russia and the modern world], 1, 118-132. (In Russ.)

14. Ermolenko, G. V., Proskuryakova, L. I. \& Ermolenko, B. V. (2017). Switching to renewables: what will Russia gain? Foresight, 19(5), 528-540.

15. Chaplygina M. A. \& Belousov R. S. (2017). World experience of Autonomous power supply for the Russian hinterland. Alleya nauki [Alley of science], 2(16), 464-474. (In Russ.)

16. Elliott, D. (2013). Renewables: A Review of Sustainable Energy Supply Options. New York, NY: IOP Publishing Ltd, 158. 
17. Shere, J. (2013). Renewable: The World-Changing Power of Alternative Energy. New York, NY: St. Martin's Press, 304.

18. Sørensen, B. (2017). Renewable Energy: Physics, Engineering, Environmental Impacts, Economics \& Planning, Fifth Edition. New York, N.Y.: Academic Press, 1056.

19. Rehfeldt, K. (1996). Windenergie nutzung in der Bundesrepublin Deutchland. DEWI Magazin, 9, 15-27. (In German)

20. Twidell, J. W. \& Weir, A. D. (1986). Renewable Energy resources. London: F. N. Spon, 391.

21. Cirelli, J. F \& Sire, D. (2007). L'énergie est un secteur où il faut être grand. Nouvelles Fondations, 2, 75-78. (In French)

22. Burrows, M. \& Treverton, G. (2008). Strategic View of the Energy Future. Washington: GPO, 142.

23. Surzhikova, O. A. (2010). Power Supply of Hard-to-Reach, Sparsely Populated and Remote Areas. Regionalnaya ekonomika: teoriya i praktika [Regional economics: theory and practice], 11, 67-72. (In Russ.)

24. Kuzhuget, S. A. \& Kenden, K. V. (2018). Prospects for the development of decentralized energy in the Republic of Tuva. In: Aktualnye voprosy energetiki. Mat-ly vseros. nauch.-prakt. konf. s mezhdunar. uchastiem. 17 maya 2018 [Urgent issues of energy. Materials of the all-Russian scientific-practical conference with international participation] (pp. 185-187). Omsk. (In Russ.)

25. Voronkova, O. Yu., Yakimova, L. A., Frolova, I. I., Shafranskaya, Ch. Ya., Kamolov, S. G. \& Prodanova, N. A. (2019). Sustainable development of territories based on the integrated use of industry, resource and environmental potential. International Journal of Economics and Business Administration, (7)2, 151-163.

26. Velkin, V. I. (2015). Metodologiya rascheta kompleksnykh sistem VIE dlya ispolzovaniya na avtonomnykh obektakh [Methodology for calculating integrated RES systems for using on Autonomous objects]. Ekaterinburg: UrFU, 225. (In Russ.)

27. Bashmakov, I. A., Borisov, K. B., Dzedzichek, M. G., Lebedev, O. V. \& Lunin A. A. (2017). Low-Carbon solutions against the «Economy of compression». Ekologicheskiy vestnik Rossii [Ecological Bulletin of Russia], 11, 14-20

28. Kanygin, P. S. (2010). Alternative energy in the EU: opportunities and limits. Ekonomist [Economist], 1, 57. (In Russ.)

29. Dakalov M. V. (2015). Ekonomicheskie aspekty razvitiya vozobnovlyaemykh istochnikov energii v stranakh ES : diss. kand. ekon. nauk [Economic aspects of the development of renewable energy sources in the EU countries. Thesis of PhD in economics]. Moscow. (In Russ.)

30. Levin, Yu. A. \& Pavlov, A. O. (2017). Far Eastern investment projects: the impact of electricity prices on the financial performance. Finansovyy biznes [Financial business], 1(186), 31-34. (In Russ.)

31. Asaul, A. N., Sagaan-Ool, K. B. \& Sevek, V. K. (2014). Formirovanie i realizatsiya promyshlennoy politiki regiona [Formation and implementation of industrial policy of the region]. Kyzyl: TuvGU, 167. (In Russ.)

32. Dongak, B. A. (2015). Organizatsiya predprinimatelskoy deyatelnosti posredstvom sozdaniya etnoklasterov $v$ Respublike Tyva : diss. kand. ekon. nauk [Organization of business activities through the creation of ethno-clusters in the Republic of Tyva. Thesis of PhD in economics]. Saint-Petersburg, 159. (In Russ.)

\section{Информация об авторах}

Асаул Анатолий Николаевич - доктор экономических наук, профессор, ФГБОУ ВО «Санкт-Петербургский государственный архитектурно-строительный университет», профессор кафедры экономики строительства и ЖKX; Scopus Author ID: 55816361100; http://orcid.org/ 0000-0002-7415-4737 ( Российская Федерация, 190005 СанктПетербург, 2-я Красноармейская ул., 4; 188660 Ленинградская обл., д. Порошкино,1-й проезд, 5; e-mail: asaul@ yandex.ru).

Асаул Максим Анатольевич - доктор экономических наук, профессор, ФГБОУ ВО «Московский автомобильно-дорожный государственный технический университет»; профессор кафедры экономики автомобильного транспорта; Scopus Author ID: 57209097491; http://orcid.org/ 0000-0003-3040-5765 (Российская Федерация, 125319 Москва, Ленинградский проспект, 64; Ленинградская обл., д. Порошкино, 1-й проезд, д.5; e-mail: m-a-asaul@mail. $\mathrm{ru})$.

Левин Юрий Анатольевич - доктор экономических наук, профессор, ФГАОУ ВО Московский государственный институт международных отношений (университет) Министерства иностранных дел России; профессор кафедры экономики и финансов; Scopus Author ID: 57211605513; ORGID ID: 0000-0002-9568-7866 ( Российская Федерация, 119454 Москва, проспект Вернадского, 76; 119136 гор. Москва, Сетуньский 2-й пр,, 19, кв. 51; е-таil: levin25@mail.ru).

Платонов Анатолий Михайлович - доктор экономических наук, профессор, Институт экономики и управления, профессор кафедры «Экономика и управление строительством и рынком недвижимости», ФГАОУ ВО 'Уральский федеральный университет имени первого Президента России Б.Н. Ельцина; Scopus Author ID : 56106151900; ORCID: http://orcid.org/0000-0002-1199-0578 (Российская Федерация, 620002, г. Екатеринбург, ул. Мира, 19; 620142, г. Екатеринбург, ул. Щорса, 54а, кв. 34; e-mail: a.m.platonov@urfu.ru, e-mail : eusrn@mail.ru).

\section{About the Authors}

Anatoliy N. Asaul - Dr. Sci. (Econ.), Professor, Department of Construction Economics and Housing and Utility Infrastructure, Saint Petersburg State University of Architecture and Civil Engineering; Scopus Author ID: 55816361100; http://orcid.org/0000-0002-7415-4737 (4, 2-aya Krasnoarmeyskaya St., Saint Petersburg, 190005, Russian Federation; e-mail: asaul@yandex.ru). 
Maksim A. Asaul - Dr. Sci. (Econ.), Professor, Department of Economics of Automobile Transport, Moscow Automobile and Road Construction State Technical University; Scopus Author ID: 57209097491; http://orcid.org/ 0000-0003-30405765 (64, Leningrad Ave., Moscow, 125319, Russian Federation; e-mail: m-a-asaul@mail.ru).

Yuri A. Levin - Dr. Sci. (Econ.), Professor, Department of Economics and Finance, MGIMO University; Scopus Author ID: 57211605513; http://orcid.org/0000-0002-9568-7866 (76, Vernadskogo Ave., Moscow, 119454, Russian Federation; e-mail: levin25@mail.ru).

Anatoliy M. Platonov - Dr. Sci. (Econ.), Professor, School of Economics and Management, Academic Department of Economics and Management in Construction and Real Estate Market, Ural Federal University; Scopus Autor ID: 56106151900; http://orcid.org/0000-0002-1199-0578 (19, Mira St., Ekaterinburg, 620002, Russian Federation; e-mail: a.m.platonov@urfu.ru,e-mail: eusrn@mail.ru).

Дата поступления рукописи: 16.02.2020.

Прошла рецензирование: 14.04.2020.

Принято решение о публикации: 10.06.2020. 